\title{
THROMBOANGIITIS OBLITERANS OF CORONARY AND INTERNAL THORACIC ARTERIES IN A YOUNG WOMAN
}

Francesco Donatelli, MD, ${ }^{a}$ Michele Triggiani, $\mathrm{MD}, \mathrm{PhD},{ }^{\mathrm{a}}$ Simona Nascimbene, MD, ${ }^{\mathrm{a}}$ Cristina Basso, $\mathrm{MD},{ }^{\mathrm{c}}$ Stefano Benussi, MD, ${ }^{a}$ Sergio L. Chierchia, MD, FESC, FACC, ${ }^{\mathrm{b}}$ Gaetano Thiene, MD, ${ }^{\mathrm{c}}$ and Adalberto Grossi, MD, ${ }^{\mathrm{a}}$ Milan and Padua, Italy

Coronary artery disease may rarely be due to vasculitis. Angina pectoris and acute myocardial infarction have been reported in patients with Takayasu's disease, polyarteritis nodosa, and thromboangiitis obliterans..$^{1{ }^{1}}$

In this article we report a case of Buerger's disease localized to coronary and internal thoracic arteries (ITAs) in a young nonsmoking woman. The diagnosis was made by histologic examination of the ITAs that were discarded at the time of bypass surgery.

A 39-year-old woman had a 2-year history of epigastric pain of unknown origin and sporadic episodes of typical angina for the past 8 months. Because of worsening of symptoms she underwent a treadmill exercise test, which showed signs of myocardial ischemia. The patient appeared to be otherwise in good health, without evidence of risk factors including diabetes mellitus, hypercholesterolemia, hypertension, obesity, or family history of isch-

From the Department of Thoracic and Cardiovascular Surgery, University of Milan, ${ }^{\text {a }}$ the Department of Cardiology, Scientific Institute HS Raffaele, ${ }^{\mathrm{b}}$ Milan, Italy, and the Department of Pathology, Univeristy of Padua, ${ }^{c}$ Padua, Italy.

Received for publication Feb. 22, 1996; accepted for publication March 18, 1996.

J Thorac Cardiovasc Surg 1997;113:800-2

Copyright (C) 1997 by Mosby-Year Book, Inc.

$0022-5223 / 97 \$ 5.00+0 \quad \mathbf{1 2 / 5 4 / 7 3 5 3 2}$

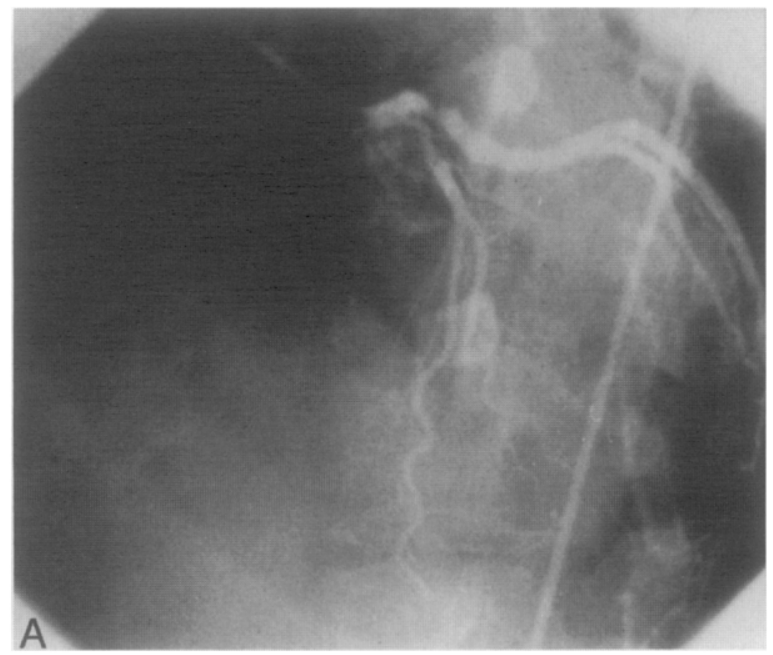

emic heart disease. She had never smoked. She never had aphthous ulcerations in the mouth or genitalia, nor had she a history of bronchial asthma, rash, fever, myalgia, or arthralgia. Routine blood assays were all within normal limits with the exception of the erythrocyte sedimentation rate $(35 \mathrm{~mm} / \mathrm{hr})$. Because of unstable angina, the patient underwent cardiac catheterization, which showed severe left main disease (Fig. 1, $A$ ) and critical stenoses of the right coronary artery (Fig. $1, B$ ) necessitating urgent myocardial revascularization. After a standard median sternotomy, both ITAs were dissected but were found to be unsuitable for grafting because of diffuse narrowing at the proximal end and occlusion at the distal end. Moreover, satellite lymph nodes were enlarged. Three coronary arteries were bypassed with saphenous veins: the left anterior descending artery and the first obtuse marginal branch had a small caliber $(<1.5 \mathrm{~mm})$, and the posterior descending artery was thickened. The postoperative course was uneventful.

Vascular specimens were examined histologically. The ITAs showed occlusion of the lumen owing to fibrous hyaline tissue with evidence of neovascularity, in keeping with an organized thrombus, with an intact internal elastic membrane and tunica media (Fig. 2, A). The vein specimen showed intimal clusters of granulocytes with superimposed mural thrombosis (Fig. 2, $B$ ). The artery and the vein were surrounded by fat with signs of periadventitial fibrosis involving neural structures and by lymph nodes

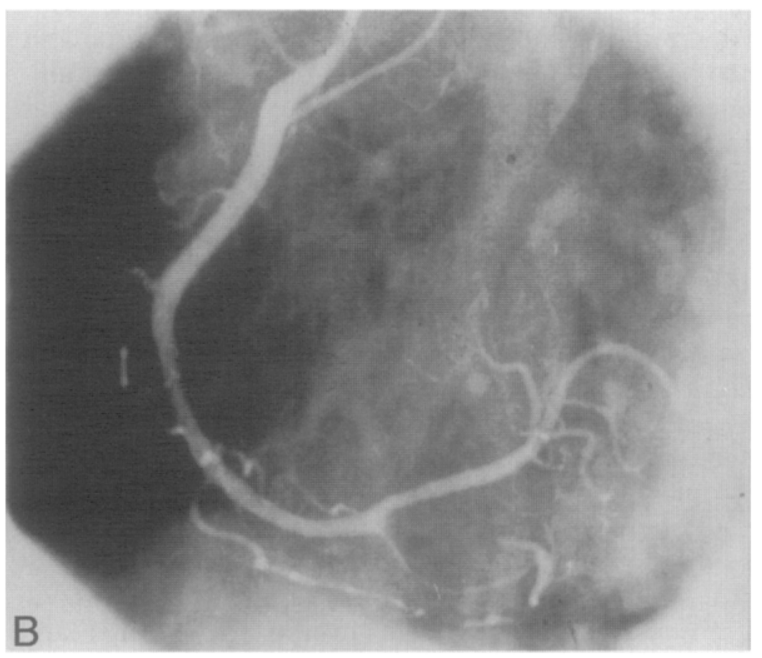

Fig. 1. Angiograms in the left anterior oblique projection showing stenosis of the left main coronary artery (A) and the right coronary artery (B). 
Volume 113, Number 4
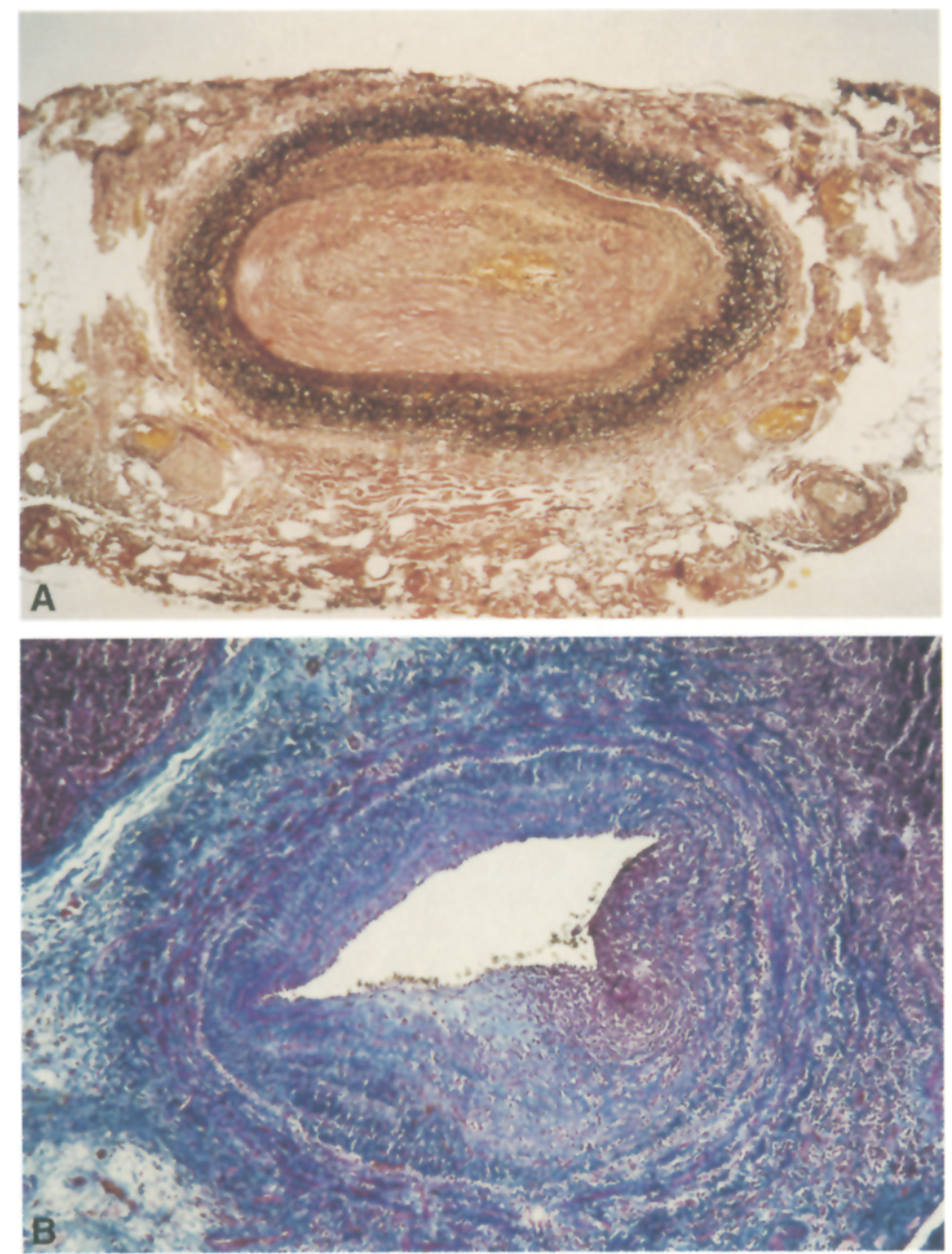

Fig. 2. Histologic studies of the ITA and saphenous vein graft. A, ITA occluded by organized thrombosis with intact internal elastic lamina and tunica media (Weigert-Van Gieson stain; original magnification $\times 60$ ). B, Vein with focal intimal abscess (Azan Mallory stain; original magnification $\times 100$ ).

with follicular hyperplasia. The diagnosis was consistent with thromboangiitis obliterans. Anti-core, anti-mitochondrial, anti-smooth muscle, anti-cardiolipin, anti-ribosome, and anti-reticulin antibodies and rheumatoid factor were not detected. Measurements of $\mathrm{C} 3$ and $\mathrm{C} 4$ in the blood, as well as nephroscintigraphy, were within normal limits.

At 8 months' follow-up the patient was doing well and was free of recurrent angina. Blood assays were within normal ranges with the exception of an elevated concentration of serum lipoprotein(a) $(36.1 \mathrm{mg} / \mathrm{dl}$ with a cutoff of $20 \mathrm{mg} / \mathrm{dl}$ ).

Buerger's disease may involve vessels other than those of the extremities. ${ }^{5}$ Acute myocardial infarction owing to involvement of epicardial coronary arteries has been reported to be prevalent in affected patients. ${ }^{6}$ However, so far as we know, this is the first case of solitary localization of thromboangiitis obliterans in the chest involving both coronary arteries and ITAs. The diagnosis was made by histologic examination of ITAs discarded at operation, which showed thrombotic occlusion and intimal abscesses with an intact internal elastic lamina and tunica media. Before the operation, the diagnosis of Buerger's disease in this nonsmoking woman was unsuspected, because women are rarely affected by Buerger's disease ${ }^{7}$ and smoking is considered a major cause. However, histologic features were pathognomonic and other types of vasculitis (Behcet's disease, polyarteritis nodosa, Kawasaki's syndrome, vasculitis in systemic lupus erythematosus and rheumatoid arthritis, Churg-Strauss disease, Takayasu's arteritis, and Wegener's granulomatosis) were excluded by clinical history, blood assays, and histologic studies. 
Thromboangiitis obliterans is a nonatherosclerotic inflammatory occlusive vascular disease of unknown origin. In the absence of smoking, other risk factors, such as serum lipoprotein(a), must be considered in the pathogenesis of this disease. ${ }^{8}$ Even though 8 months after the operation the patient had returned to her normal activities, the prognosis will be influenced by the potential, and previously reported occurrence of thromboangiitis obliterans in the aorta-coronary saphenous vein grafts. ${ }^{9}$

\section{REFERENCES}

1. Amano J, Suzuki A. Coronary artery involvement in Takayasu's arteritis. J Thorac Cardiovase Surg 1991;102:554-60.

2. Pick RA, Glover MU, Vieweg MVR. Myocardial infarction in a young woman with isolated coronary arteritis. Chest 1992; 82:378-80.

3. Ohno H, Matsuda Y, Takashiba K, Hamada Y, Ebihara H,
Hyakuna E. Acute myocardial infarction in Buerger's disease. Am J Cardiol 1986;57:690-1.

4. Saphir O. Thromboangiitis obliterans of the coronary arteries and its relation to arteriosclerosis. Am Heart J 1936;12:521-35.

5. Mills JL, Porter JM. Thromboangiitis obliterans (Buerger's disease). In: Churg A, Churg J, Hunder GG, editors. Systemic vasculitis. Tokyo: Igaku-Shoin, 1991:229-39.

6. Goodman RM, Elian B, Mozes M, Deutsch B. Buerger's disease in Israel. Am J Med 1965;39:601-15.

7. Laslett LJ, Ikeda RM, Mason DT. Female adolescent Buerger's disease: objective documentation and therapeutic remission. Am Heart J 1981;102:452-6.

8. Takami S, Kubo M, Yamashita S, et al. High levels of serum lipoprotein(a) in patients with ischemic heart disease with normal coronary angiogram and thromboangiitis obliterans. Atherosclerosis 1995;112:253-60.

9. Lie JT. Thromboangiitis obliterans (Buerger's disease) in a saphenous vein arterial graft. Hum Pathol 1987;18:402-4.

\title{
ADDITIONAL POSTBYPASS ADMINISTRATION OF TRANEXAMIC ACID REDUCES BLOOD LOSS AFTER CARDIAC OPERATIONS
}

\author{
Junya Katoh, MD, Kouji Tsuchiya, MD, Wataru Sato, MD, Masato Nakajima, MD, and Yoshinao Iida, MD, \\ Yamanashi, Japan
}

Excessive bleeding after cardiac operations involving cardiopulmonary bypass (CPB), mostly a result of activated fibrinolysis and platelet dysfunction, remains a problem. Intraoperative administration of aprotinin significantly decreases postbypass blood loss; however, its use is limited because of complications such as inadequate heparinization during CPB and high cost. ${ }^{1}$ Alternatively, Karski and associates ${ }^{2}$ revealed that high-dose administration of tranexamic acid (TA) before CPB prevents excessive postoperative blood loss and reduces the need for blood transfusions. TA inhibits fibrinolysis by binding to the lysine binding site on plasminogen and plasmin, which is the binding site for fibrin.

It was reported that to counteract post-CPB fibrinolytic status and achieve hemostasis, high-dose TA administration was needed. ${ }^{3}$ The elimination half-life of TA is about 80 minutes. To maintain concentrations of TA in the

From the Department of Cardiovascular Surgery, Yamanashi Central Hospital, Kofu, Yamanashi, Japan.

Received for publication Oct. 8, 1996; accepted for publication Oct. 22, 1996.

Address for reprints: Junya Katoh, MD, Second Department of Surgery, Yamanashi Medical University, 1110 Shimokato, Tamaho-cho, Nakakoma-gun, Yamanashi, 409-38 Japan.

J Thorac Cardiovase Surg 1997;113:802-4

Copyright (c) 1997 by Mosby-Year Book, Inc.

$0022-5223 / 97 \$ 5.00+0 \quad \mathbf{1 2 / 5 4 / 7 8 7 6 7}$ blood during hemostasis after $\mathrm{CPB}$, we gave an additional half of the pre-CPB dose of TA during the post-CPB period. The objective of this study was to investigate whether an additional postbypass dose of TA affects post-CPB blood loss after cardiac operations:

Methods. Ninety-three patients undergoing either coronary artery bypass grafting or heart valve operation were studied with their informed consent. Approval for the study was received from our hospital's ethics review board. Only one cardiac surgeon (K. T.) was involved in the study. In this prospective, randomized trial, the patients were divided into three groups of equal size. Patient characteristics are summarized in Table I.

All patients received high-dose fentanyl anesthesia. Before CPB was established, heparin, $200 \mathrm{IU} / \mathrm{kg}$, was given intravenously to each patient. Additional heparin was added throughout CPB to maintain the activated clotting time at more than 400 seconds. Heparin was neutralized with protamine sulfate with the use of dose-response curves. Group TA-1 patients received an infusion of TA, $100 \mathrm{mg} / \mathrm{kg}$, intravenously, over 20 minutes soon after induction of anesthesia and before CPB. Group TA-2 patients received a 100 $\mathrm{mg} / \mathrm{kg}$ dose of TA, like the group TA-1 patients, and an additional TA dose of $50 \mathrm{mg} / \mathrm{kg}$ infused intravenously over 20 minutes soon after being weaned from CPB. Control group patients received conventional perioperative therapy. Red blood cells (RBCs) were transfused for a hemoglobin threshold of $75 \mathrm{gm} / \mathrm{L}$ or less. Mediastinal blood loss during the operation, but after discontinuation of CPB, and drain- 